\title{
Characterization of DNA hydroxymethylation in the hypothalamus of elderly mice with post-operative cognitive dysfunction
}

\author{
JIANG ZHONG and WEI XU \\ Department of Anesthesiology, Jinshan Hospital, Fudan University, Shanghai 201508, P.R. China
}

Received November 9, 2018; Accepted August 13, 2019

DOI: $10.3892 /$ etm.2019.8056

\begin{abstract}
Post-operative cognitive dysfunction (POCD) is a common syndrome characterized by perioperative cerebral damage in elderly patients, including cognitive impairment and memory loss. Recent studies have revealed that anesthesia is one of the key causes of POCD. Ubiquitin-like with PHD and ring finger domains 2 (Uhrf2) has been reported to play a crucial role in regulating DNA methylation and hydroxymethylation, which are closely connected with memory building and erasure. However, whether narcotic drugs can affect Uhrf2 to impact on DNA methylation and hydroxymethylation in POCD is poorly understood. In this study, a POCD model was established in elderly mice through sevoflurane treatment, and these mice were found to have compromised levels of global DNA 5'-hydroxymethylcytosine $(5 \mathrm{hmC})$ and Uhrf2 in the hippocampus and the amygdaloid nucleus, when compared with non-POCD and control mice. The results of immunoprecipitation and quantitative PCR revealed that $5 \mathrm{hmC}$ modification of the promoters of genes associated with neural protection and development, such as glial cell-derived neurotrophic factor, brain derived neurotrophic factor, glucocorticoid receptor and acyl-CoA sythetase short chain family member 2, was reduced in the hippocampus of POCD mice when compared with non-POCD and control mice. Taken together, the findings of the present study suggest that loss of $5 \mathrm{hmC}$, in the hippocampus and the amygdaloid nucleus modulated by Uhrf 2 suppression, may result in the learning and memory ability impairment seen in mice with POCD.
\end{abstract}

\section{Introduction}

Post-operative cognitive dysfunction (POCD) is a common syndrome in elderly patients, usually occurring in the first

Correspondence to: Dr Wei Xu, Department of Anesthesiology, Jinshan Hospital, Fudan University, 1508 Longhang Road, Jinshan, Shanghai 201508, P.R. China

E-mail: xuwei198208@163.com

Key words: post-operative cognitive dysfunction, 5'-hydroxymethylcytosine, ubiquitin-like with PHD and ring finger domains 2 , sevoflurane several weeks or months after an operation. It results in dysfunction of the central nervous system, including cognitive impairment, declining learning and memory ability, information processing disorder and delirium (1). Clinical methodological differences between POCD studies, including the use of variable batteries of tests, lack of control groups, loss of patients during follow-up and inconsistent intervals between testing periods, limit their usefulness (2). Due to the lack of formal diagnostic criteria, as well as the subtlety of the cognitive changes that occur, assessment and diagnosis of POCD is difficult (3).

The causes of POCD in elderly patients are thought to be multifactorial and complex. One potential risk factor for POCD is the use of anesthetic agents (4). Widely used narcotics are currently classified into inhalational and intravenous anesthetics (5). Inhalational general anesthetics such as isoflurane and halothane have been demonstrated to increase the risk of Alzheimer's disease (AD) in the aging brain (6), and exert a neurotoxic effect via caspase-mediated apoptosis (7).

One proposed hypothesis is that epigenetic regulation influenced by anesthetic may be a critical mechanism underlying POCD (8). Despite the similar pathological change in neurocytes with AD, the epigenetic alteration in POCD predominantly results in memory and learning disabilities (9). DNA hydroxymethylation is a novel modification based on DNA methylation catalyzed by dioxygenases. Hydroxymethylated cytosine $(5 \mathrm{hmC})$ is identified as an intermediate of the active demethylation process $(10,11) .5 \mathrm{hmC}$ is highly distributed in the early embryo, embryonic stem cells (12) and the nervous system $(13,14)$. Recent studies have revealed that the level of $5 \mathrm{hmC}$ is reduced by $10 \%$ after ten-eleven translocation methylcytosine dioxygenase 1 (TET1) knockdown, which can retard the proliferation of neural progenitor cells and impair the abilities of spatial learning and memory $(15,16)$. Moreover, a reduction in $5 \mathrm{hmC}$ modulates transcriptional activity of some genes involved in neurogenesis in AD mice, which also indicates that $5 \mathrm{hmC}$ is closely connected with memory maintenance $(17,18)$. Along with the TET family, ubiquitin-like with PHD and ring finger domains 2 (Uhrf2) is also considered to be a novel regulator of $5 \mathrm{hmC}$ via its SET and ring finger associated domain $(19,20)$. Aberrant distribution of $5 \mathrm{hmC}$ may be one of the possible molecular causes of POCD occurrence. The major enzymes that contribute to $5 \mathrm{hmC}$ metabolism affected by anesthetic in POCD are also poorly understood. 
In this study DNA hydroxymethylation in the central neural system of POCD mice was profiled in an attempt to reveal the underlying pathogenesis of POCD caused by anesthetic.

\section{Materials and methods}

Animal study. All procedures were approved by the Institutional Animal Care and Use Committee of Fudan University, Jinshan Hospital (Animal protocol number 2017-32-166). A total of 170 18-month-old outbred female C57BL/6 mice, purchased from Shanghai SLAC Laboratory Animal Co., Ltd., were used in this study. The levels of glucose and oxygen saturation $(\mathrm{SpO} 2)$ in $50 \mu \mathrm{l}$ blood isolated from the caudal vein were determined using a biochemical analyzer (Beckman Coulter Inc.). IL-1 $\beta$ levels were analyzed in a further $50 \mu \mathrm{l}$ blood using ELISA kits (cat. no. PMLB00C; R\&D Systems Inc.). Animals were fed with standard food and water ad libitum. A total of 150 randomly selected mice were treated with $2 \%$ sevoflurane for $2 \mathrm{~h}$ (21-23) in an anesthesia chamber with a size of $25 \times 13 \times 13 \mathrm{~cm}$. The remaining 20 mice were treated with normal air, as a negative control. In a pilot study $2 \%$ sevoflurane treatment was tested for $4 \mathrm{~h}$, but $>50 \%$ of mice died upon this condition (data not shown).

The Morris water maze test (post-treatment 2-7 days) and open field test (post-operative day 7) were performed as previously described $(24,25)$ in order to verify the POCD model. In brief, for the Morris water maze test, a platform was set in the center of a $0.5 \mathrm{~m}$ high and $1.2 \mathrm{~m}$ in diameter pool, $5 \mathrm{~cm}$ above the water surface. Mice were trained at the same entrance for a total of $2 \mathrm{~min}$ each time for a total of 6 times from the 2 nd to 7 th day after sevoflurane treatment (one exposure). The motion trail, the escape period and the distance travelled were recorded. For the open field test, mice were put in a $30 \times 72 \times 72 \mathrm{~cm}$ box, with light conditions that mimicked daytime. During the 5 min the mice spent in the box, their average distance travelled, total grid crossings, distance travelled around the central region and duration spent in the central region were recorded. Both an escape period of $<90 \mathrm{sec}$ after the 7 th day of sevoflurane treatment and an open field score of $<25 \%$ were considered as cognitive damage consistent with a POCD model $(26,27)$.

The mice were sacrificed on day 7 by cervical dislocation. For each mouse, all brain tissues including hippocampus, amygdaloid nucleus and cerebellum were harvested and separated into two parts. One was fixed by $1 \%$ paraformaldehyde at room temperature $\geq 24 \mathrm{~h}$ for DNA dot blot assay, Methylated DNA immunoprecipitation (MeDIP) and immunofluorescence assay, while the other is washed by cold PBS and treated with RIPA buffer (Solarbio Inc.) or TRIzol ${ }^{\circledR}$ reagent (Invitrogen; Thermo Fisher Scientific, Inc.) accordingly for western blotting and PCR.

DNA dot blot assay. A total of $2 \mu 1$ genomic DNA was extracted from tissues (Qiagen $\mathrm{GmbH}$ ) and was dropped onto each nitrocellulose membrane at a 2-fold serial dilution $(0,5,10$, 20 and $40 \mathrm{ng}$ ) for dot blot assay. The spots were dried at room temperature and incubated in TBST with antibodies against 5hmC (cat. no. ab214728; Abcam) or 5-methylcytosine (5mC; cat. no. ab10805; Abcam) (1:500 dilution; $1 \mathrm{ng} / \mathrm{ml})$ in $10 \mathrm{ml}$ of TBS-T for $4 \mathrm{~h}$ overnight with gentle shaking. The membranes were washed with TBS-T three times for 10 min each time at room temperature, followed by goat anti-mouse IgG-HRP (1:10,000 dilution; $20 \mathrm{ng} / \mathrm{ml}$; A0216, Beyotime Institute of Biotechnology) or goat anti-rabbit IgG-HRP (1:10,000 dilution; $20 \mathrm{ng} / \mathrm{ml}$; A0208, Beyotime Institute of Biotechnology) incubation in $10 \mathrm{ml}$ of TBST for $1 \mathrm{~h}$ at room temperature with gentle shaking, and washed again three times. BSA (New England Biolabs Inc.) was used as a negative control. Membranes were subsequently incubated with $3 \mathrm{ml}$ of ECL Western Blotting Substrate (Beyotime Institute of Biotechnology) for $5 \mathrm{~min}$ in darkness at room temperature to develop the bands by Tanon 5200 Chemiluminescence Imaging Analysis System.

Western blot analysis. Brain tissues were homogenized in RIPA buffer and then centrifuged at $4^{\circ} \mathrm{C}$ and $12,000 \mathrm{x}$ g for $10 \mathrm{~min}$. The protein quantity in the supernatant was determined using a BCA protein assay kit (E162-01; Fansbio). Equal amounts of total $40 \mu \mathrm{g}$ protein samples were separated by $10 \%$ sodium dodecyl sulfate-polyacrylamide gel electrophoresis (SDS-PAGE) and transferred to polyvinylidene fluoride membranes. The membranes were then blocked using $5 \%$ non-fat milk in TBS at $4^{\circ} \mathrm{C}$ for $90 \mathrm{~min}$ and then incubated with the respective primary antibodies against TET1 $(1: 2,000$; cat. no. ab191698; Abcam), TET2 (1:2,000; cat. no. ab124297; Abcam), Uhrf1 (1:2,000; cat no. 12387; Cell Signaling Technology, Inc.), Uhrf2 (1:2,000; cat. no. ab28673; Abcam) and $\beta$-actin (1:5,000; cat. no. AA128; Beyotime Institute of Biotechnology) overnight at $4^{\circ} \mathrm{C}$. Membranes were washed with TBST and incubated with goat anti-mouse and goat anti-rabbit IgG-HRP (1:10,000; 20 ng/ml, Beyotime Institute of Biotechnology) at room temperature for $1 \mathrm{~h}$. Membranes were then treated with aBM Chemiluminescence Western Blotting Kit (cat. no. 11520709001; EMD Millipore), and the bands were captured to evaluate the difference of protein expression.

Immunofluorescence assay. In brief, mouse tissue was fixed using 4\% paraformaldehyde at room temperature for $24 \mathrm{~h}$ then dehydrated with $50-90 \%$ ethanol. Samples were permeabilized in 50\% xylene-ethanol at room temperature for $30 \mathrm{~min}$ then in $50 \%$ xylene-paraffin at $60^{\circ} \mathrm{C}$ for $15 \mathrm{~min}$ and embedded. Tissues were cut into $5 \mu \mathrm{m}$ sections and washed with $0.3 \% \mathrm{H}_{2} \mathrm{O}_{2}$-methanol for $10 \mathrm{~min}$ then heated to $92^{\circ} \mathrm{C}$ for 40 min for antigen retrieval. Following PBS washing, sections were blocked with 5\% BSA (Sigma-Aldrich; Merck KGaA) for $30 \mathrm{~min}$ at $37^{\circ} \mathrm{C}$. Subsequently, slices were incubated with 5hmC (1:200; cat. no. ab214728; Abcam) and Uhrf2 (1:200; cat no. ab28673; Abcam) antibodies overnight at $4^{\circ} \mathrm{C}$. After washing, tissues were further incubated with the appropriate Alexa Fluor secondary antibody (cat. no. A32732; Thermo Fisher Scientific, Inc.) at 1:20,000 dilution for $30 \mathrm{~min}$ at room temperature. After washing, cells were mounted in mounting media with DAPI (Vector Laboratories Inc.). The positive staining of $5 \mathrm{hmC}$ and Uhrf2 were digitally captured by Olympus BX51 (Olympus Corporation) at x400 magnification and analyzed using ImageJ software v1.8.0 (National Institutes of Health).

MeDIP quantitative (q) PCR assay. MeDIP assay was performed as previously described (28). Extracted genomic 
Table I. Sequences of primers used.

A, Med IP assay

\begin{tabular}{|c|c|c|}
\hline Target & Primer sequence $\left(5^{\prime}-3^{\prime}\right)$ & Length of PCR products \\
\hline ACSS2 & $\begin{array}{l}\text { CCCAGACCATAACAGTACCGACTC } \\
\text { CGCCTTTGCCATTCATAGAGC }\end{array}$ & 294 \\
\hline BDNF & $\begin{array}{l}\text { TTAGAGGAGGTGTAGCCTTGTT } \\
\text { TTGTCATCACAGTGGGAAGC }\end{array}$ & 223 \\
\hline CCL2 & $\begin{array}{l}\text { AAAGTTTCCATTGCTGCTGCTC } \\
\text { TCTGATGTAACGGGCTCTTGG }\end{array}$ & 106 \\
\hline FAS & $\begin{array}{l}\text { АСТTСССТАССCACCCATTC } \\
\text { AAAGTACCCAAGGAGCTAAAGG }\end{array}$ & 220 \\
\hline GCR & $\begin{array}{l}\text { ATTGCCCTGGATGCCTGTAA } \\
\text { ATGACCATGAACCTCCTGAA }\end{array}$ & 321 \\
\hline GDNF & $\begin{array}{l}\text { ATGGCTCTATGCTGCTTTGC } \\
\text { TATCCCAGACGTGGACTTGC }\end{array}$ & 163 \\
\hline GLUR2 & $\begin{array}{l}\text { GAGGGTGGAATGGGAAAGAG } \\
\text { AGGCAGCTACCAAATGTCTCG }\end{array}$ & 197 \\
\hline HMGB1 & $\begin{array}{l}\text { TTTTCCTTCTTTGGGTCTAA } \\
\text { CCAGCCTAACTCTGCTTCCT }\end{array}$ & 217 \\
\hline MMP9 & $\begin{array}{l}\text { TGGTTTCAGAAGAGGAGGACAGG } \\
\text { GCAGCGAGGAACAGGGAGCA }\end{array}$ & 248 \\
\hline
\end{tabular}

B, qPCR assay

\begin{tabular}{|c|c|c|}
\hline Target & Primer sequence $\left(5^{\prime}-3^{\prime}\right)$ & Length of PCR products \\
\hline \multirow[t]{2}{*}{ ACSS2 } & TCCCATTCTTCGGTGTAGCG & 376 \\
\hline & GTAACAAAGCAGTAGAGGCATTCG & \\
\hline \multirow[t]{2}{*}{ BNDF } & GTGGGTCACAGCGGCAGATA & 203 \\
\hline & ACGATTGGGTAGTTCGGCATT & \\
\hline \multirow[t]{2}{*}{ CCL2 } & AAGAAGGAATGGGTCCAGACA & 140 \\
\hline & GCTTCAGATTTACGGGTCAACT & \\
\hline \multirow[t]{2}{*}{ FAS } & TCTGGGCTGTCCTGCCTCTG & 111 \\
\hline & CAGTTTCACGAACCCGCCTC & \\
\hline \multirow[t]{2}{*}{ GCR } & TGGAATAGGTGCCAAGGGTC & 171 \\
\hline & GCAGAGTTTGGGAGGTGGTC & \\
\hline \multirow[t]{2}{*}{ GDNF } & GATGAAGTTATGGGATGTCGTGG & 175 \\
\hline & TGCCGCTTGTTTATCTGGTGA & \\
\hline \multirow[t]{2}{*}{ GLUR2 } & GAAGCCTCAGAAGTCCAAACC & 342 \\
\hline & TTAGCCGTGTAGGAGGAGATG & \\
\hline \multirow[t]{2}{*}{ HMGB1 } & ATCCTGGCTTATCCATTGGTG & 244 \\
\hline & ТССТСАТССТСТТСАТССТССТ & \\
\hline \multirow[t]{2}{*}{ MMP9 } & AAGGGTACAGCCTGTTCCTGGTG & 146 \\
\hline & GATGCCGTCTATGTCGTCTTTATTCA & \\
\hline
\end{tabular}

MedIP, methylated DNA immunoprecipitation; ACSS2, acyl-CoA synthetase short chain family member 2; BDNF, brain derived neurotrophic factor; CCL2, C-C motif chemokine ligand 2; FAS, fas cell surface death receptor; GCR, glucocorticoid receptor; GDNF, glial cell-derived neurotrophic factor; GluR2, glutamate receptor 2 precursor; HMGB1, high mobility group protein B1; q, quantitative; MMP9, matrixmetallopeptidase-9.

DNA was sonicated (90 cycles of $30 \mathrm{sec}$ on/30 sec off with high power; UCD-300; Bioruptor) and incubated with $0.5 \mu \mathrm{g}$
5hmC (cat. no. ab214728; Abcam) or 5mC (cat. no. ab10805; Abcam) antibody or IgG (cat. no. A0208, Beyotime Institute 
of Biotechnology) as control overnight to capture the DNA fragment with $5 \mathrm{hmC}$ or $5 \mathrm{mC}$, then washed and harvested for detection of the $5 \mathrm{hmC}$ or $5 \mathrm{mC}$ enrichment at promoter regions of candidate genes, where the primers for $\mathrm{qPCR}$ were designed to encompass $\sim 200 \mathrm{bp}$ (Table I). The qPCR reactions were done using the Fast Universal SYBR Green Realtime PCR Master Mix (Roche Diagnostics) and in triplicate under the following conditions: $95^{\circ} \mathrm{Cv}$ for $30 \mathrm{sec} ; 40$ cycles of $95^{\circ} \mathrm{C}$ for $5 \mathrm{sec}$ and $60^{\circ} \mathrm{C}$ for $30 \mathrm{sec}$. Ct value was analyzed to calculate enrichment using the $2^{-\Delta \Delta \mathrm{Cq}}$ method (29).

Reverse transcription-quantitative (RT-q)PCR. Total RNA was extracted using TRIzol ${ }^{\circledR}$ reagent according to the manufacturer's instructions. Before performing RT, RNA was treated with 5U DNase I (Beyotime Institute of Biotechnology) on ice for $10 \mathrm{~min}$ to remove bacterial genomic DNA, and purified using isopropanol and $3 \mathrm{M}$ sodium acetate, before washing with $75 \%$ ice ethanol. Reverse transcription was performed as the conditions of $42^{\circ} \mathrm{C}$ for $15 \mathrm{~min}$ and $95^{\circ} \mathrm{C}$ for 3 min using the QuantiTect Reverse Transcription kit (Qiagen $\mathrm{GmbH}$ ). qPCR were performed using Fast Universal SYBR Green Realtime PCR Master (Roche Diagnostics) with the conditions followed were $95^{\circ} \mathrm{C}$ for $30 \mathrm{sec} ; 40$ cycles of $95^{\circ} \mathrm{C}$ for $5 \mathrm{sec}$ and $60^{\circ} \mathrm{C}$ for $30 \mathrm{sec}$ using the primers listed in Table I.

Statistical analysis. To distinguish between the non-POCD and POCD groups, the escape latency values of control group at post-operative day 7 were collected and fitted a normal distribution as $\mu \pm \sigma$. Normal samples were distributed within the range from $\mu-3 \sigma$ to $\mu+3 \sigma$ by $99.73 \%$ probability. Thus, the values included or excluded in $\mu \pm 3 \sigma$ were considered as non-POCD or POCD respectively. Likewise, the values of distance travelled as well as the data of open field test including average distance, grid crossings numbers, distance among central region and staying time among central region were all analyzed in the same way. Finally, the intersection of the potential POCD from each type of parameters was confirmed as the POCD group. Data are presented as the mean \pm standard deviation for multiple independent experiments. The multiple comparisons of the difference between values were analyzed using one-way ANOVA. The pairwise comparisons of control group and POCD/non-POCD groups were analyzed using Fisher's Least Significant Difference post hoc test following ANOVA. Pearson's correlation analysis was used to evaluate the association between $5 \mathrm{mC}$ and $5 \mathrm{hmC}$ and the mRNA level. $\mathrm{P}<0.05$ was considered to indicate a statistically significant difference.

\section{Results}

5hmC expression is altered in mice with cognitive dysfunction. Initial levels of blood glucose, $\mathrm{SpO} 2$ and IL-1 $\beta$ were analyzed in order to rule out respiratory depression, infection or hypoglycemia, because these physical signs were subject to POCD occurrence (Table II). A total of 150 mice were treated with 2\% sevoflurane in order to establish a POCD model. A total of 18 of these mice were identified as having POCD via both Morris water maze test and an open field test daily between 2 and 7 days post-operatively (Fig. 1A; Table II). Unlike POCD in humans, which happens most conspicuously on post-operative 
A
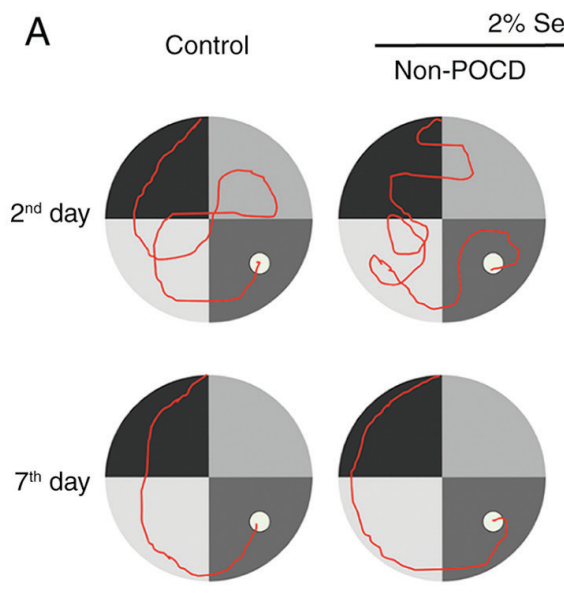

$2 \%$ Sevoflurane
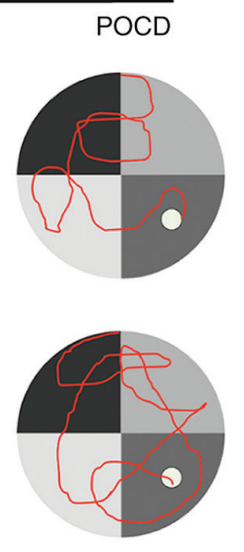

$\mathrm{B}$

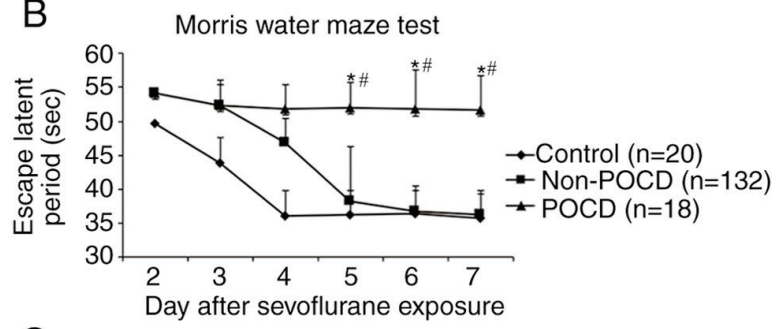

$\mathrm{C}$

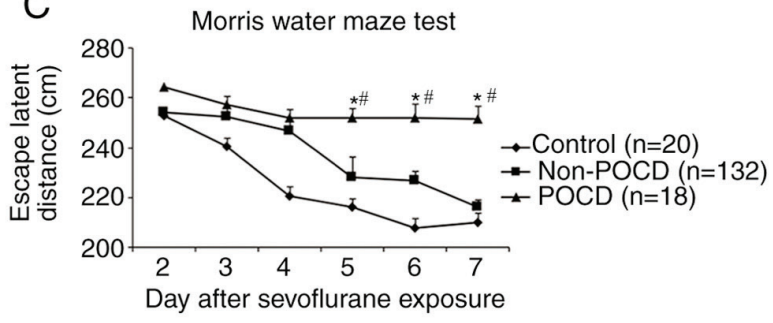

Figure 1. Verification of a POCD mouse model using Morris water maze test. (A) The movement route. (B) Escape latency period. (C) Distance travelled by mice in the control, non-POCD and POCD groups. All data are presented as the mean \pm standard deviation of each group. ${ }^{*} \mathrm{P}<0.05$ vs. control and ${ }^{\#} \mathrm{P}<0.05$ vs. non-POCD groups. POCD, post-operative cognitive dysfunction.

day 7 and at post-operative month 3 (30), POCD mice started to display increasing escape latency and travelled distance from the 5th day when compared to control and non-POCD mice (Fig. 1B and C). The mice were sacrificed at day 7 and the brain tissues harvested to detect global $5 \mathrm{hmC}$ expression via dot blot assay. The presence of differential change of global $5 \mathrm{hmC}$ expression in whole brain lysate before and after POCD was observed (n=3; Fig. 2A and B). Furthermore, the hippocampus, amygdaloid nucleus and cerebellum were also harvested on day 7 and it was observed that $5 \mathrm{hmC}$ was significantly lower in POCD mice compared to control in the hippocampus and amygdaloid nucleus, but no obvious change was seen in the cerebellum ( $n=5$; Fig. $2 \mathrm{C}$ and D). There were no differences in $5 \mathrm{mC}$ level between POCD and control $(\mathrm{n}=5$; Fig. 2E and F). Taken together, the loss of $5 \mathrm{hmC}$ in both the hippocampus and amygdaloid nucleus was observed in POCD mice and it may be responsible for the cognitive impairment seen, including the loss of abilities of memory, spatial learning, and new environmental adaptation.

Loss of Uhrf2 is responsible for $5 \mathrm{hmC}$ alteration in hippocampus of POCD mice. To elucidate the hydroxymethylation impacted by POCD, the enzymes Uhrf1, Uhrf2, TET1 and TET2 for $5 \mathrm{hmC}$ were investigated via western blotting. The protein levels of Uhrf1, TET1 and TET2 exhibited no significant differences between control and POCD in whole brain, whilst Uhrf2 displayed a slight downregulation in POCD ( $n=5$; Fig. 3A). When considering the background noise from the whole brain, Uhrf2 was further investigated in specific regions of brain and observed a suppression in hippocampus and amygdaloid nucleus in POCD compared with control ( $\mathrm{n}=5$; Fig. $3 \mathrm{~B}$ and $\mathrm{C}$ ), coinciding with the change of $5 \mathrm{hmC}$. Collectively, Uhrf2 was suppressed by sevoflurane for hindrance of $5 \mathrm{hmC}$ in POCD.

POCD results in $5 \mathrm{hmC}$ reduction at the promoter regions of genes associated with neurodevelopment. The present study hypothesized that Uhrf 2 may be responsible for $5 \mathrm{hmC}$ maintenance in hippocampus and amygdaloid nucleus. To further validate the role of $5 \mathrm{hmC}$ in $\mathrm{POCD}$, the local $5 \mathrm{mC}$ and $5 \mathrm{hmC}$ enrichment at promoter regions of genes associated with neurodevelopment was detected through MedIP-qPCR. Glial cell-derived neurotropic factor (GDNF), brain-derived neurotrophic factor (BDNF), glucocorticoid receptor (GCR) and acyl-CoA synthetase short chain family member 2 (ACSS2) displayed a reduced $5 \mathrm{hmC}$ (Fig. 4A) and unvaried $5 \mathrm{mC}$ (Fig. 4B) level on their promoters in POCD compared with control (control $\mathrm{n}=5$; POCD $\mathrm{n}=6$ ). Compared with their transcriptional levels (Fig. 4C), 5hmC levels on the promoters of GDNF, BDNF, GCR and ACSS2 could reflect the transcriptional activation of these genes (Figs. 4D and S1). While 5mC levels on the promoters of MMP9, HGMB1 and GLUR2 showed an inverse tendency with transcription of these genes (Fig. 4B and D). Additionally, neither $5 \mathrm{hmC}$ nor $5 \mathrm{mC}$ of FAS and CCL2 had any correlation with their mRNA change in POCD compared to control.

\section{Discussion}

In the present study, $2 \%$ sevoflurane was used to establish a POCD model. Mouse models of POCD displayed signs of behavioral and memory problems $(27,31)$, as indicated by the results of water maze and open field tests. By contrast, the results for the non-POCD group were similar to the normal control. Although certain phenotypes have been studied to classify early POCD, such as serum proteomics (32), cerebrospinal fluid (33), and cerebral oxygen saturation (34), no clear test for the susceptibility of individuals to POCD is available.

Due to a lack of potent drug for the treatment of POCD in clinical practice, a previous study has prompted the use of DNA methyltransferase inhibitors, which can restore memory-associated transcriptional regulation and improve behavioral memory function in elderly animals (8). However, the role of epigenetic factors in POCD has not been previously investigated to the best of our knowledge. The current study demonstrated an association between $5 \mathrm{hmC}$ and POCD, and aimed to clarify the role of hydroxymethylation in POCD for the regulation of memory and learning ability. The global $5 \mathrm{hmC}$ 


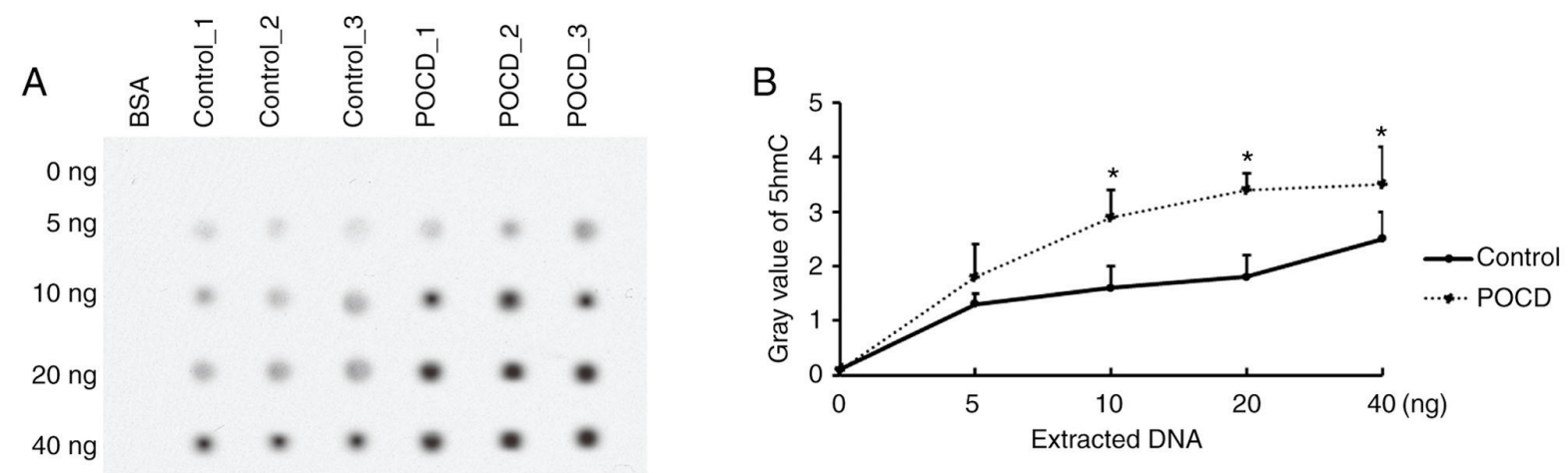

DNA weight of samples per $\mu \mathrm{l}$


DNA weight of samples per $\mu \mathrm{l}$

Figure 2. Characterization of $5 \mathrm{hmC}$ level in the brain of POCD mice. The global $5 \mathrm{hmC}$ level of whole brain using (A) dot blot assay and (B) statistical analysis. The $5 \mathrm{hmC}$ distribution in hippocampus, amygdaloid nucleus and cerebellum using (C) immunofluorescence and (D) statistical analysis. The global $5 \mathrm{mC}$ level of whole brain using (E) dot blot assay and (F) statistical analysis. Gray value was defined as the mean of the integrated optical density of the pixels in the selection. All data are presented as the mean \pm standard deviation of the mean of five independent experiments. ${ }^{*} \mathrm{P}<0.05$ vs. control group. $5 \mathrm{hMC}, 5 \mathrm{hydroxy}-$ methylcytosine; BSA, bovine serum albumin; POCD, post-operative cognitive dysfunction.

level in brain was reduced in POCD. However, of the different brain regions, $5 \mathrm{hmC}$ levels in hippocampus and amygdaloid nucleus declined the most markedly in the POCD group, which implies that $5 \mathrm{hmC}$ may contribute to memory and learning ability in the hippocampus (35) as well as fear emotion control in the amygdaloid nucleus (36). However, the presence of unaltered $5 \mathrm{hmC}$ levels in the cerebellum before and after POCD, suggests that the basic associative learning and memory from cerebellum impaired by POCD (37) may be independent of accumulation or loss of hydroxymethylation (37). The expression levels of hydroxymethylation associated enzymes such as Uhrf1 and TETs remained unchanged, while the decreased protein levels of Uhrf2 in POCD were consistent with $5 \mathrm{hmC}$ levels both in the hippocampus and the amygdaloid nucleus. A previous study reported that TET1 knockout did not affect overall brain morphology in mice, and concluded that TET1 

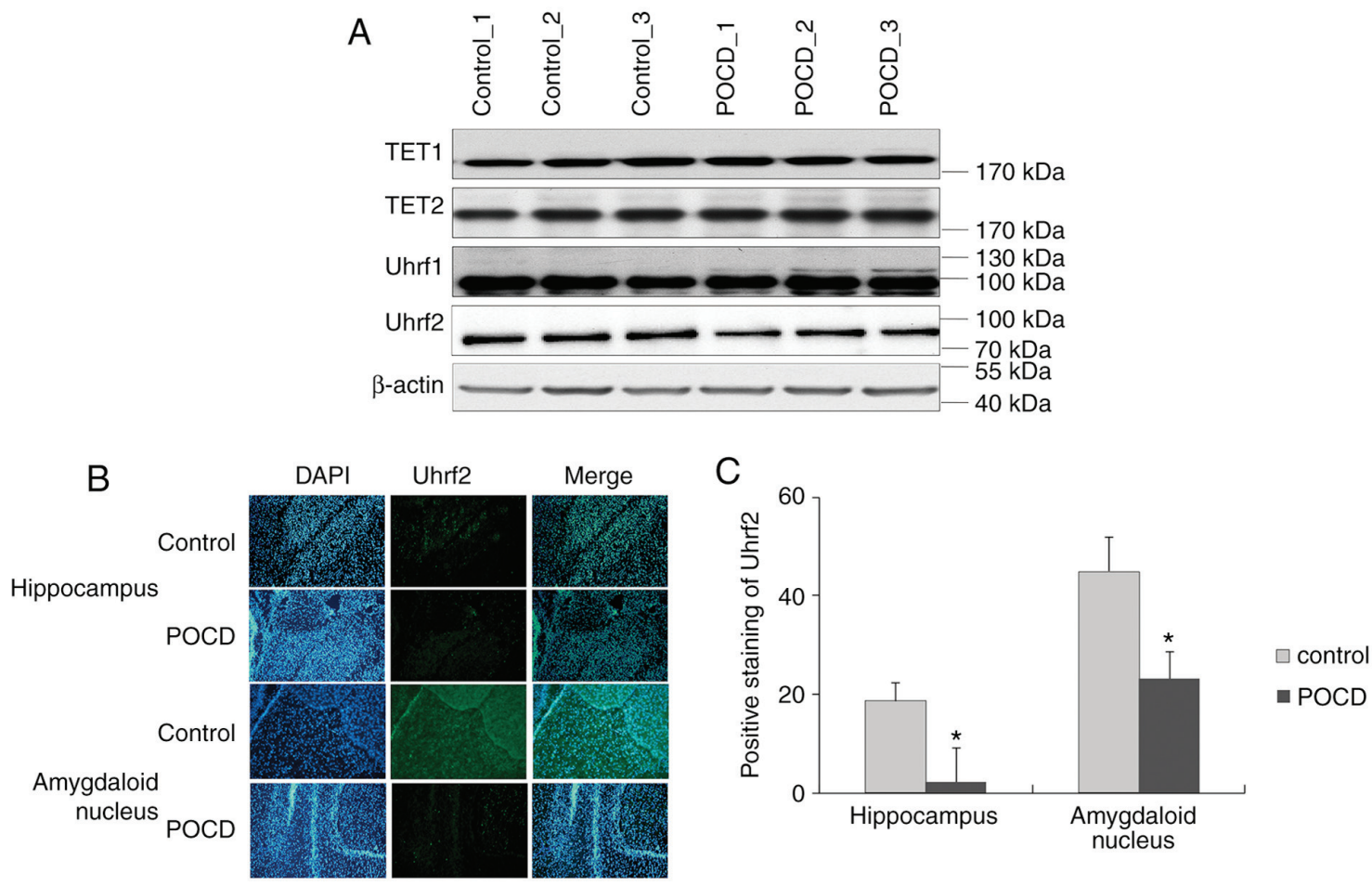

Figure 3. Expression of Uhrf2 in the brain of POCD mice. (A) The protein expression levels of enzymes associated with hydroxymethylation were evaluated in the whole brain using western blotting. The Uhrf2 protein distribution in hippocampus and amygdaloid nucleus using (B) immunofluorescence and (C) statistical analysis. All data are presented as the mean \pm standard deviation of the mean of five individual experiments. "P $<0.05$ vs. control group. POCD, post-operative cognitive dysfunction; TET 1/2, ten-eleven translocation methylcytosine dioxygenase 1/2; Uhrf 2, ubiquitin like with PHD and ring finger domains 2.
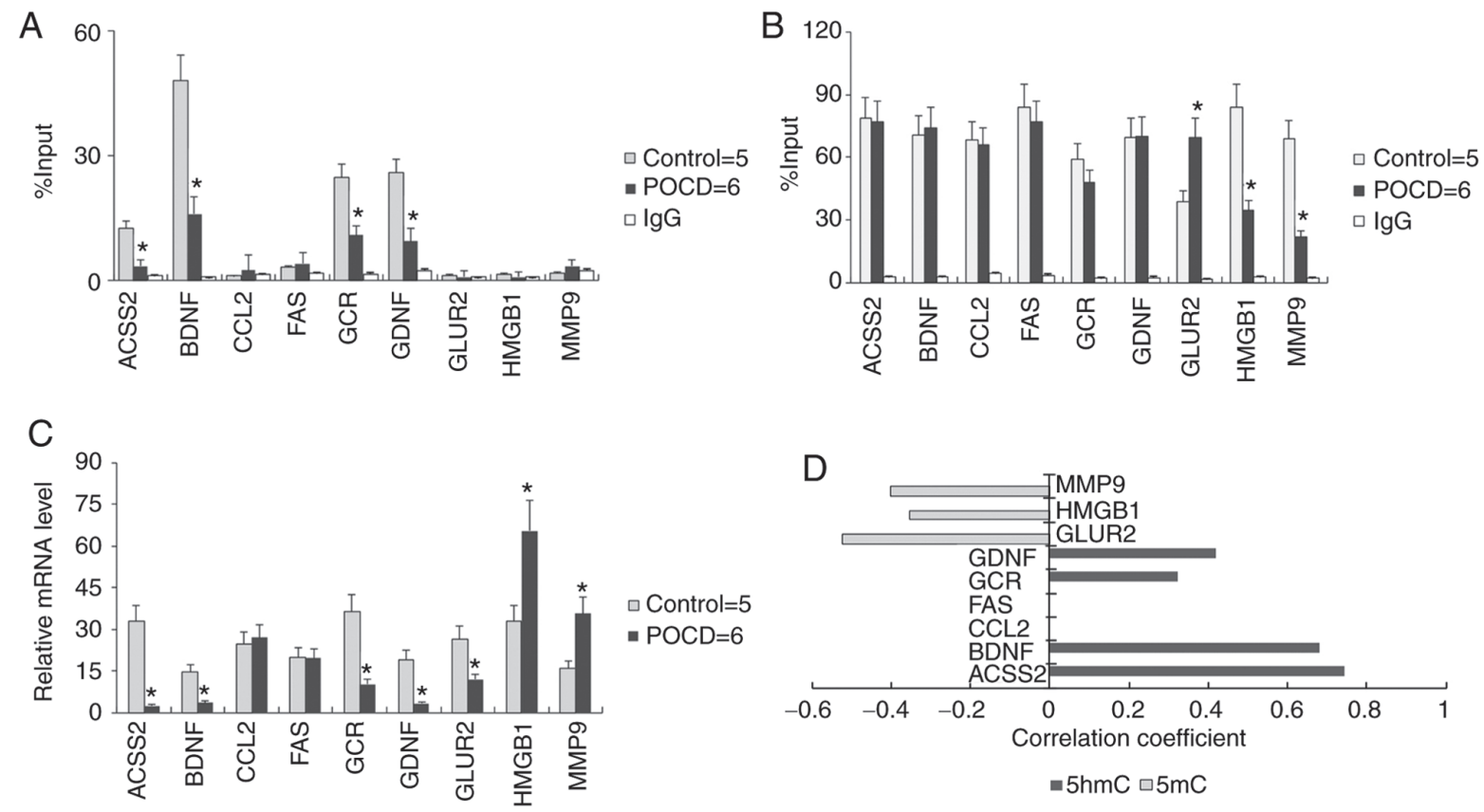

Figure 4. Association between $5 \mathrm{hmC}$ and gene transcription. Local (A) $5 \mathrm{hmC}$ and (B) $5 \mathrm{mC}$ enrichment at promoter regions of genes associated with neurodevelopment. (C) Transcriptional level of nine genes in mouse brain. (D) The significant difference $\mathrm{P}<0.05$ between $5 \mathrm{mC}$ or $5 \mathrm{hmC}$ enrichment and mRNA level are listed. All data are presented as the mean \pm standard deviation of the mean of individual experiments (control for five; POCD for six duplications). ${ }^{*} \mathrm{P}<0.05$ vs. control group. $5 \mathrm{hmC}, 5$ 'hydroxymethylcytosine; $5 \mathrm{mC}, 5$ 'methylcytosine; ACSS2, acyl-CoA synthetase short chain family member 2 ; BDNF, brain derived neurotrophic factor; CCL2, C-C motif chemokine ligand 2; FAS, fas cell surface death receptor; GCR, glucocorticoid receptor; GDNF, glial cell-derived neurotrophic factor; GluR2, glutamate receptor 2 precursor; HMGB1, high mobility group protein B1; MMP9, matrixmetallopeptidase-9.

deletion could enhance the consolidation and storage of threat recognition (cued and contextual fear conditioning) and object location memories (38), which is apparently reciprocal with the phenotype of POCD. It is therefore unlikely that TET 
levels exert an effect in POCD. A recent study reported that loss of Uhrf2 reduced $5 \mathrm{hmC}$ in the brain, including the cortex and hippocampus, but did not change $5 \mathrm{mC}$ level, and that mice exhibited a partial impairment in spatial memory acquisition and retention (20), which was further confirmed by the current results. The results of the present study suggest that Uhrf2 may be a target responding to $5 \mathrm{hmC}$ regulation in POCD.

The relationship between $5 \mathrm{hmC}$ enrichment and gene transcription in POCD was further investigated. Two epigenetic means of gene transcriptional regulation closely associated with neurodevelopment, DNA methylation-mediated gene silencing and loss of DNA hydroxymethylation-mediated gene silencing were identified in the current study. $5 \mathrm{hmC}$ was reduced in ACSS2, BDNF, GCR and GDNF, while 5mC levels for these genes remained unaltered, which indicated that sevoflurane can suppress Uhrf 2 to compromise the $5 \mathrm{hmC}$ modification on the promoter regions of these genes associated with neuroprotection and proliferation and thereby repress the transcriptional activity. Moreover, the change of expression of GLUR2, HMGB1 and MMP9 were significantly negative correlated with their DNA methylation change at promoter level. This may be due to a change in DNA methylation patterns in their promoters.

The molecular mechanism underlying the differences between non-POCD and POCD remains to be elucidated. We hypothesized that it depends on individual factors, such as neuroplasticity, immunity and the sensitivity to sevoflurane. However, it is difficult to distinguish differences in the epigenetic patterns of brain tissues from a group of animals as variations exist between each individual. Once POCD develops, samples of the diseased brain in its pre-diseased normal state cannot be obtained. A further limitation is that incidence of POCD in both humans and mouse models is low. In addition, sevoflurane treatment may not be an optimal model for POCD induction. In future studies a rapid method for delirium induction by scopolamine (39) or another sedative may be a better way to mimic and further study POCD. An additional limitation of this study is that genetic editing (over-expression or knockdown in vivo) operation of the $5 \mathrm{hmC}$ metabolism associated enzymes such as Tet1/2/3 or Uhrf1/2 was not performed to further investigate the sevoflurane-induced effect of learning and memory impairment as well as $5 \mathrm{hmC}$ loss in POCD model.

Overall, the current data suggest that sevoflurane may lead to the suppression of Uhrf2 and induce the loss of global $5 \mathrm{hmC}$ in the hippocampus and amygdaloid nucleus, thereby impairing the learning and memory ability of mice with POCD. The present study revealed a novel connection between $5 \mathrm{hmC}$, which is an important biomarker of memory and POCD. The current findings may provide a new biomarker to target or inform the development of a new anesthetic to reduce the incidence of POCD.

\section{Acknowledgements}

Not applicable.

\section{Funding}

This study was supported by the Science \& Technology Commission of Jinshan District, Shanghai (grant no. 2017-3-09).

\section{Availability of data and materials}

The data sets used and/or analyzed during the current study are available from the corresponding author on reasonable request.

\section{Authors' contributions}

JZ performed experiments and analyzed the data. WX designed the project and drafted the paper.

\section{Ethics approval and consent to participate}

This study was approved by the Institutional Animal Care and Use Committee of Fudan University, Shanghai (animal protocol number 2017-32-166) and all animal protocols were conducted following the guidelines accordingly.

\section{Patient consent for publication}

Not applicable.

\section{Competing interests}

The authors declare that they have no competing interests.

\section{References}

1. Pappa M, Theodosiadis N, Tsounis A and Sarafis P: Pathogenesis and treatment of post-operative cognitive dysfunction. Electron Physician 9: 3768-3775, 2017

2. Funder KS, Steinmetz J and Rasmussen LS: Methodological issues of postoperative cognitive dysfunction research. Semin Cardiothorac Vasc Anesth 14: 119-122, 2010.

3. Monk TG and Price CC: Postoperative cognitive disorders. Curr Opin Crit Care 17: 376-381, 2011.

4. Tzimas P, Samara E, Petrou A, Korompilias A, Chalkias A and Papadopoulos G: The influence of anesthetic techniques on postoperative cognitive function in elderly patients undergoing hip fracture surgery: General vs spinal anesthesia. Injury 49: 2221-2226, 2018.

5. Amare M, McEvoy M and Smith A: The effect of intravenous and inhalational maintenance of anaesthesia on postoperative cognitive outcomes in elderly people. Anaesthesia 74: 1068 , 2019.

6. Eckenhoff RG, Johansson JS, Wei H, Carnini A, Kang B, Wei W, Pidikiti R, Keller JM and Eckenhoff MF: Inhaled anesthetic enhancement of amyloid-beta oligomerization and cytotoxicity. Anesthesiology 101: 703-709, 2004.

7. Xie Z, Culley DJ, Dong Y, Zhang G, Zhang B, Moir RD, Frosch MP, Crosby G and Tanzi RE: The common inhalation anesthetic isoflurane induces caspase activation and increases amyloid beta-protein level in vivo. Ann Neurol 64: 618-627, 2008.

8. Wang Y, Chen Z, Zhao Y, Shi R, Wang Y, Xu J, Wu A, Johns RA and Yue Y: Epigenetics as a new therapeutic target for postoperative cognitive dysfunction. Med Hypotheses 80: 249-251, 2013.

9. Sweatt JD: Neuroscience. Epigenetics and cognitive aging. Science 328: 701-702, 2010.

10. Wu X and Zhang Y: TET-mediated active DNA demethylation: Mechanism, function and beyond. Nat Rev Genet 18: 517-534, 2017.

11. Ito S, Shen L, Dai Q, Wu SC, Collins LB, Swenberg JA, He C and Zhang Y: Tet proteins can convert 5-methylcytosine to 5-formylcytosine and 5-carboxylcytosine. Science 333: 1300-1303, 2011.

12. Ito S, D'Alessio AC, Taranova OV, Hong K, Sowers LC and Zhang Y: Role of Tet proteins in $5 \mathrm{mC}$ to $5 \mathrm{hmC}$ conversion, ES-cell self-renewal and inner cell mass specification. Nature 466: 1129-1133, 2010.

13. Mellén M, Ayata P, Dewell S, Kriaucionis S and Heintz N: $\mathrm{MeCP} 2$ binds to $5 \mathrm{hmC}$ enriched within active genes and accessible chromatin in the nervous system. Cell 151: 1417-1430, 2012. 
14. Kriaucionis S and Heintz N: The nuclear DNA base 5-hydroxymethylcytosine is present in Purkinje neurons and the brain. Science 324: 929-930, 2009.

15. Zhang RR, Cui QY, Murai K, Lim YC, Smith ZD, Jin S, Ye P, Rosa L, Lee YK, Wu HP, et al: Tet1 regulates adult hippocampal neurogenesis and cognition. Cell Stem Cell 13: 237-245, 2013.

16. Rudenko A, Dawlaty MM, Seo J, Cheng AW, Meng J, Le T, Faull KF, Jaenisch R and Tsai LH: Tet1 is critical for neuronal activity-regulated gene expression and memory extinction. Neuron 79: 1109-1122, 2013.

17. Shu L, Sun W, Li L, Xu Z, Lin L, Xie P, Shen H, Huang L, $\mathrm{Xu} \mathrm{Q}$, Jin P and Li X: Genome-wide alteration of 5-hydroxymenthylcytosine in a mouse model of Alzheimer's disease. BMC Genomics 17: 381, 2016.

18. Bernstein AI,Lin Y,StreetRC,Lin L,DaiQ, YuL,BaoH, Gearing M, Lah JJ, Nelson PT, et al: 5-Hydroxymethylation-associated epigenetic modifiers of Alzheimer's disease modulate Tau-induced neurotoxicity. Hum Mol Genet 25: 2437-2450, 2016.

19. Zhou T, Xiong J, Wang M, Yang N, Wong J, Zhu B and Xu RM: Structural basis for hydroxymethylcytosine recognition by the SRA domain of UHRF2. Mol Cell 54: 879-886, 2014.

20. Chen R, Zhang Q, Duan X, York P, Chen GD, Yin P, Zhu H, $\mathrm{Xu}$ M, Chen P, Wu Q, et al: The 5-Hydroxymethylcytosine $(5 \mathrm{hmC})$ reader UHRF2 is required for normal levels of $5 \mathrm{hmC}$ in mouse adult brain and spatial learning and memory. J Biol Chem 292: 4533-4543, 2017.

21. Fang F, Lin W, Ling X, Song R, Liu Q, Lai B and Cang J: The hippocampal cyclin D1 expression is involved in postoperative cognitive dysfunction after sevoflurane exposure in aged mice. Life Sci 160: 34-40, 2016.

22. Murphy KL, McGaughy J, Croxson PL and Baxter MG: Exposure to sevoflurane anesthesia during development does not impair aspects of attention during adulthood in rats. Neurotoxicol Teratol 60: 87-94, 2017.

23. Guo S, Liu L, Wang C, Jiang Q, Dong Y and Tian Y: Repeated exposure to sevoflurane impairs the learning and memory of older male rats. Life Sci 192: 75-83, 2018.

24. Rosczyk HA, Sparkman NL and Johnson RW: Neuroinflammation and cognitive function in aged mice following minor surgery. Exp Gerontol 43: 840-846, 2008.

25. Hovens IB, Schoemaker RG, van der Zee EA, Absalom AR, Heineman E and van Leeuwen BL: Postoperative cognitive dysfunction: Involvement of neuroinflammation and neuronal functioning. Brain Behav Immun 38: 202-210, 2014.

26. Stanford SC: The open field test: Reinventing the wheel. J Psychopharmacol 21: 134-135, 2007.

27. Tang Y, Wang X, Zhang S, Duan S, Qing W, Chen G, Ye F, Le Y and Ouyang W: Pre-existing weakness is critical for the occurrence of postoperative cognitive dysfunction in mice of the same age. PLoS One 12: e0182471, 2017.

28. Zhou S, Shen Y, Zheng M, Wang L, Che R, Hu W and Li P: DNA methylation of METTL7A gene body regulates its transcriptional level in thyroid cancer. Oncotarget 8: 34652-34660, 2017.
29. Livak KJ and Schmittgen TD: Analysis of relative gene expression data using real-time quantitative PCR and the 2(-Delta Delta C(T)) method. Methods 25: 402-408, 2001.

30. Johnson T, Monk T, Rasmussen LS, Abildstrom H, Houx P, Korttila K, Kuipers HM, Hanning CD, Siersma VD, Kristensen D, et al: Postoperative cognitive dysfunction in middle-aged patients. Anesthesiology 96: 1351-1357, 2002.

31. Almahozi A, Radhi M, Alzayer S and Kamal A: Effects of memantine in a mouse model of postoperative cognitive dysfunction. Behav Sci (Basel) 9: pii: E24, 2019.

32. Zhang Q, Li SZ, Feng CS, Qu XD, Wang H, Zhang XN, Liu Y, Wang Y, Wu AS and Yue Y: Serum proteomics of early postoperative cognitive dysfunction in elderly patients. Chin Med J (Engl) 125: 2455-2461, 2012.

33. Ji MH, Yuan HM, Zhang GF, Li XM, Dong L, Li WY, Zhou ZQ and Yang JJ: Changes in plasma and cerebrospinal fluid biomarkers in aged patients with early postoperative cognitive dysfunction following total hip-replacement surgery. J Anesth 27: 236-242, 2013

34. Lin R, Zhang F, Xue Q and Yu B: Accuracy of regional cerebral oxygen saturation in predicting postoperative cognitive dysfunction after total hip arthroplasty: Regional cerebral oxygen saturation predicts POCD. J Arthroplasty 28: 494-497, 2013.

35. Webb WM, Sanchez RG, Perez G, Butler AA, Hauser RM, Rich MC, O'Bierne AL, Jarome TJ and Lubin FD: Dynamic association of epigenetic $\mathrm{H} 3 \mathrm{~K} 4 \mathrm{me} 3$ and DNA 5hmC marks in the dorsal hippocampus and anterior cingulate cortex following reactivation of a fear memory. Neurobiol Learn Mem 142: 66-78, 2017.

36. Martin-Fernandez M, Jamison S, Robin LM, Zhao Z, Martin ED, Aguilar J, Benneyworth MA, Marsicano G and Araque A: Synapse-specific astrocyte gating of amygdala-related behavior. Nat Neurosci 20: 1540-1548, 2017.

37. Jungwirth $B$, Zieglgänsberger $\mathrm{W}$, Kochs $\mathrm{E}$ and Rammes G: Anesthesia and postoperative cognitive dysfunction (POCD). Mini Rev Med Chem 9: 1568-1579, 2009.

38. Kumar D, Aggarwal M, Kaas GA, Lewis J, Wang J, Ross DL, Zhong C, Kennedy A, Song $\mathrm{H}$ and Sweatt JD: Tet1 oxidase regulates neuronal gene transcription, active DNA hydroxymethylation, object location memory and threat recognition memory. Neuroepigenetics 4: 12-27, 2015.

39. Qiu Y, Chen D, Huang X, Huang L, Tang L, Jiang J, Chen L and Li S: Neuroprotective effects of HTR1A antagonist WAY-100635 on scopolamine-induced delirium in rats and underlying molecular mechanisms. BMC Neurosci 17: 66, 2016.

This work is licensed under a Creative Commons Attribution-NonCommercial-NoDerivatives 4.0 International (CC BY-NC-ND 4.0) License. 